ORNL/TM-2016/550

\title{
Complete Status Report Documenting Weld Development for Thin Wall Tubing of ODS Ferritic Alloys
}

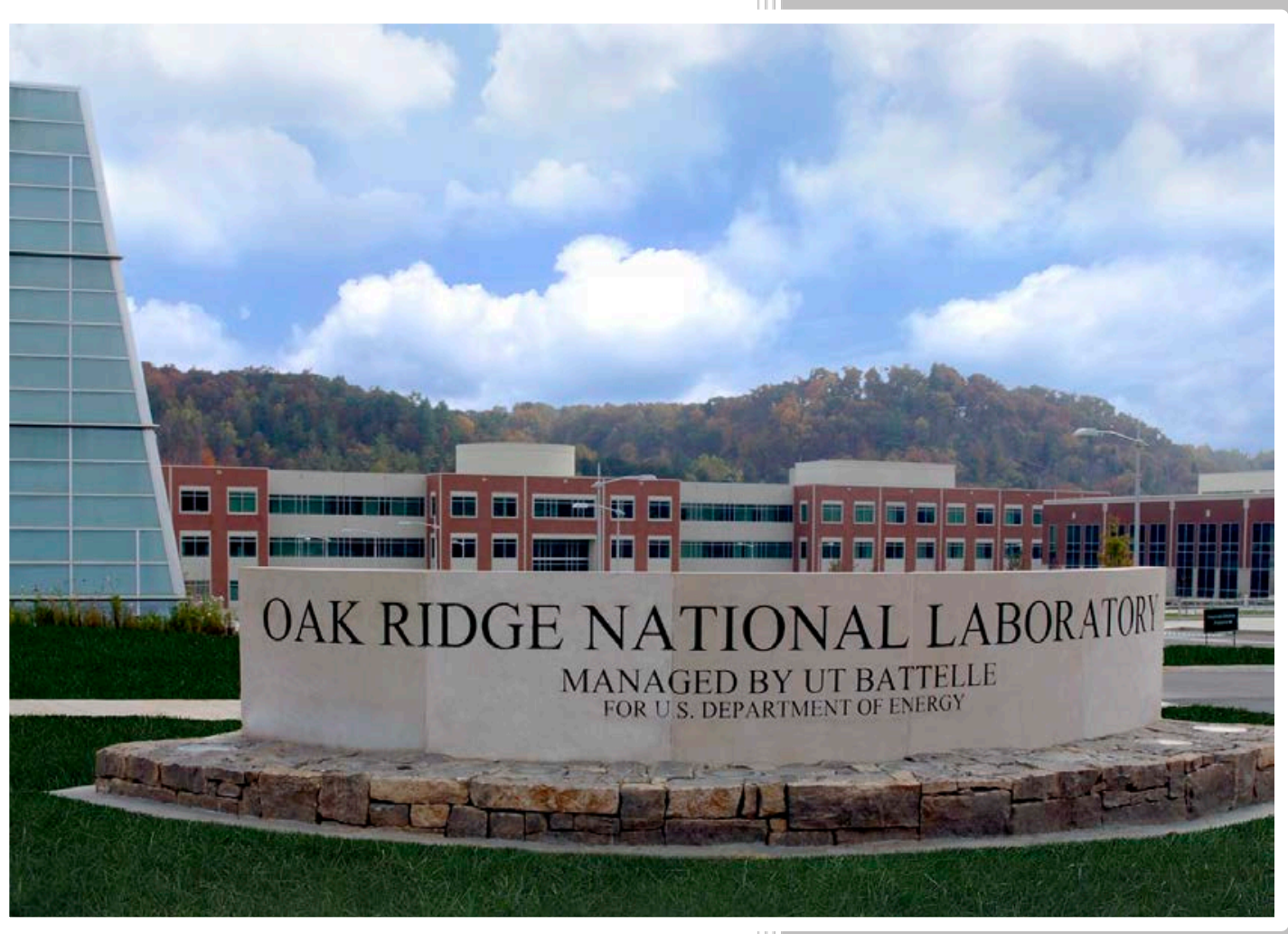

David T. Hoelzer

Phil D. Edmondson

Maxim N. Gussev

Wei Tang

Zhili Feng

September 16, 2016

Approved for public release.

Distribution is unlimited. 


\section{DOCUMENT AVAILABILITY}

Reports produced after January 1, 1996, are generally available free via US Department of Energy (DOE) SciTech Connect.

Website http://www.osti.gov/scitech/

Reports produced before January 1, 1996, may be purchased by members of the public from the following source:

National Technical Information Service

5285 Port Royal Road

Springfield, VA 22161

Telephone 703-605-6000 (1-800-553-6847)

TDD 703-487-4639

Fax 703-605-6900

E-mail info@ntis.gov

Website http://www.ntis.gov/help/ordermethods.aspx

Reports are available to DOE employees, DOE contractors, Energy Technology Data Exchange representatives, and International Nuclear Information System representatives from the following source:

Office of Scientific and Technical Information

PO Box 62

Oak Ridge, TN 37831

Telephone 865-576-8401

Fax 865-576-5728

E-mail reports@osti.gov

Website http://www.osti.gov/contact.html

This report was prepared as an account of work sponsored by an agency of the United States Government. Neither the United States Government nor any agency thereof, nor any of their employees, makes any warranty, express or implied, or assumes any legal liability or responsibility for the accuracy, completeness, or usefulness of any information, apparatus, product, or process disclosed, or represents that its use would not infringe privately owned rights. Reference herein to any specific commercial product, process, or service by trade name, trademark, manufacturer, or otherwise, does not necessarily constitute or imply its endorsement, recommendation, or favoring by the United States Government or any agency thereof. The views and opinions of authors expressed herein do not necessarily state or reflect those of the United States Government or any agency thereof. 
Fuel Cycle Research and Development (FCRD) Program

\section{Complete Status Report Documenting Weld Development for Thin Wall Tubing of ODS} Ferritic Alloys

D.T. Hoelzer, P.D Edmondson, M.N. Gussev, W. Tang and Z. Feng

Oak Ridge National Laboratory

Date Published: September 16, 2016

Prepared by

OAK RIDGE NATIONAL LABORATORY

Oak Ridge, Tennessee 37831-6283

Managed by

UT-BATTELLE, LLC

for the

US DEPARTMENT OF ENERGY

under contract DE-AC05-00OR22725 



\section{CONTENTS}

Page

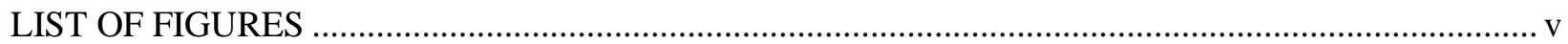

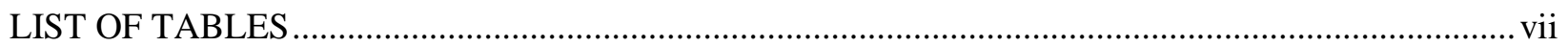

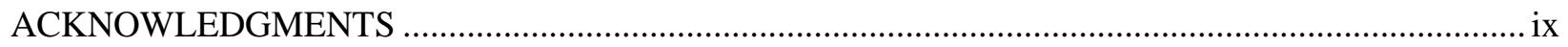

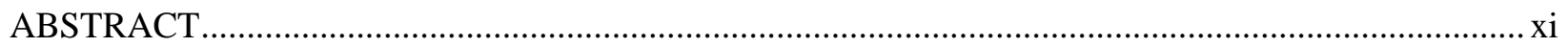

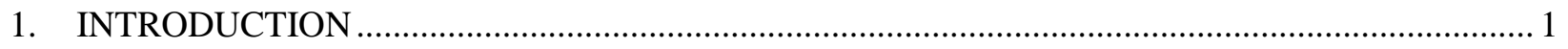

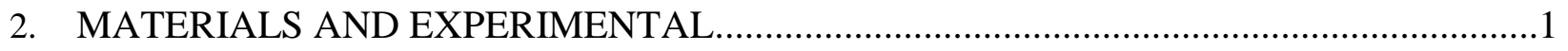

2.1 Production of $0.1 \mathrm{~cm}$ thick 14YWT plate ...................................................................... 1

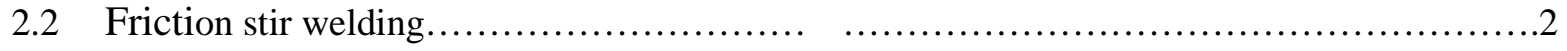

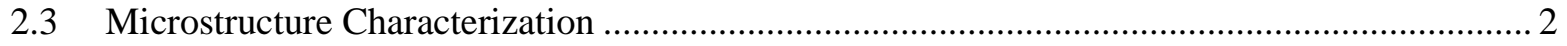

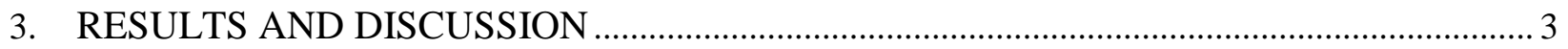

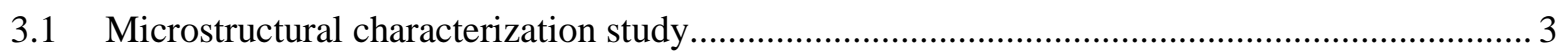

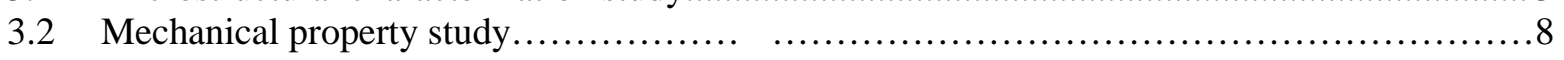

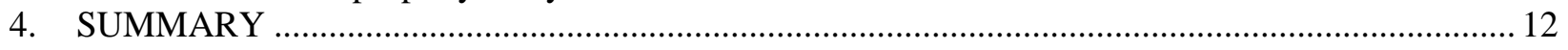





\section{LIST OF FIGURES}

Figure

Page

Figure 1. Digital image showing the $1.06 \mathrm{~cm}$ thick plate of $14 \mathrm{YWT}$ used for hot rolling to thinner thicknesses.

Figure 2. Digital image showing the $0.1 \mathrm{~cm}$ thick plate of 14YWT used in the first FSW experiment.

Figure 3. Digital image showing the bead-on-plate weld zone obtained by FSW on the $0.1 \mathrm{~cm}$ thick plate of $14 \mathrm{YWT}$....

Figure 4. Composite OM image showing the entire cross-section view of the $0.1 \mathrm{~cm}$ thick plate of 14YWT containing the FSW bead-on-plate stir zone.

Figure 5. Composite of three OM images at higher magnification showing the location and orientation of several cracks and the two lift-out/FIB specimens on the retreating side of the bead-on-plate stir zone.

Figure 6. SEM BSE image at low magnification showing the grain structure associated with the stir zone and cracks on the retreating side of the bead-on-plate stir zone....

Figure 7. BSE micrographs showing the elongated morphology and horizontal orientation of the grain structure in the unaffected zone of the FSW sample at (a) lower and

(b) higher magnifications

Figure 8. BSE micrographs showing the grain structure observed in the (a) TMAZ and (b) SZ in regions of the FSW sample located on retreating side.

Figure 9. BSE micrographs showing the grain structure observed in the SZ in the vicinity of horizontal cracks at (a) lower and (b) higher magnifications.

Figure 10. STEM micrographs (a) BF and (b) HAADF showing the grain structure observed in the SZ.

Figure 11. STEM analysis showing the presence of a large blocky-shaped TiN particle on the grain boundary, a relatively high dislocation density and a high number of Ti-rich nano-size particles associated with straight dislocations. (a) STEM BF micrograph and EDS element maps for (b) Ti and (c) N.

Figure 12. High magnification STEM-EDS results showing the distribution of Y-Ti-O particles near the junction between 3 grains. (a) BF, (b) HAADF, (c) raw XEDS maps for Fe, $\mathrm{Y}$, Ti, and $\mathrm{O}$ and (d) results of the multivariate statistical analysis of the data in (c) showing the Y-Ti-O particle distribution more clearly.

Figure 13. Template showing the layout of tensile specimens that were attempted to be fabricated from the $0.1 \mathrm{~cm}$ thick plate of 14YWT containing the bead-on-plate SZ.

Figure 14. The $0.1 \mathrm{~cm}$ thick plate of 14YWT following the abrupt crack pop-in that occurred during fabrication of the SS-1 tensile specimen by wire EDM.

Figure 15. The location the three SS-Mini-2 tensile specimens fabricated from the bead-on-plate SZ.

Figure 16. Engineering stress-strain curves of the two SS-Mini-2 specimens of 14YWT 
Figure 17. The strain distribution (Green-Lagrange strain tensor) along the gauge of specimen ${ }^{*} 4$

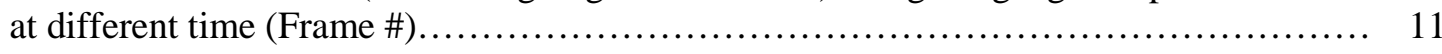

Figure 18. The strain distribution (Green-Lagrange strain tensor) along the gauge of specimen ${ }^{\#} 5$ at different time (Frame \#)............................................................ 


\section{LIST OF TABLES}

Table

Page

Table 1. Tensile properties of the two SS-Mini-2 specimens of 14YWT ...................... 10 



\section{ACKNOWLEDGMENTS}

This research was sponsored by the U.S. Department of Energy, Office of Nuclear Energy, for the Fuel Cycle Research and Development (FCRD) program.

The authors are grateful to Tom Geer for assistance in polishing metallographic samples of the FSW ODS sample and Victoria Cox for optical microscopy assistance. The authors want to also acknowledge Chad Parish for reviewing the manuscript. 



\begin{abstract}
Beginning in 2015, research in the FCRD program began the development of FSW for joining thin sections of $14 \mathrm{YWT}$ in the form of thin $(0.5 \mathrm{~mm})$ plate and ultimately thin wall tubing. In the previous fiscal year, a $1 \mathrm{~mm}$ thick plate, or sheet, of 14YWT was produced by hot rolling with no edge cracking. The initial FSW experiment was performed on the $1 \mathrm{~mm}$ thick plate and involved a bead-on-plate weld in which the spinning pin tool is plunged into the plate surface, but does not penetrate the thickness of the plate, and then travels the length of the plate. The FSW run successfully produced a bead-on-plate stir zone on the $1 \mathrm{~mm}$ thick plate of 14YWT, but no characterization studies of the stir zone were performed by the end of FY15. Therefore, the results presented in this report cover the microstructural analysis of the bead-on-plate stir zone and the initial research task on obtaining tensile properties of the stir zone using the digital image correlation (DIC) approach during testing of miniature tensile specimens to assess the quality of the FSW parameters used in the initial experiment. The results of the microstructural characterization study using optical, scanning electron and scanning transmission electron microscopies showed the grain structure in the SZ to have isotropic and irregular shape but very similar size compared to the highly elongated grains oriented horizontally with the plane of the plate that were observed in the unaffected zone of 14YWT. Several cracks oriented horizontally were observed mostly on the retreating side of the SZ in both the SZ and TMAZ. These cracks may have formed due to insufficient pressure being exerted on the top surface of the plate by the shoulder and pin tool during the FSW run. High resolution STEM-EDS analysis showed the presence of the Y-Ti-O particles in the SZ, but that some particles exhibited coarsening. Overall, the FSW parameters used to produce the bead-on-plate SZ in the $0.1 \mathrm{~cm}$ thick plate of 14YWT were nearly optimized. The results of the digital image correlation (DIC) analysis of the two SS-Mini-2 tensile specimens fabricated from the $0.1 \mathrm{~cm}$ thick plate of 14YWT showed that the specimens exhibited high strength and good ductility. However, strain localization occurred in one of the specimens during the tensile test that was too close to the grips, which invalidated the data from the DIC analysis. This was surprising since the abrupt crack pop-in that occurred in the $0.1 \mathrm{~cm}$ thick plate of 14YWT during fabrication by wire EDM suggested that residual stresses were high. Residual stress measurements and the effects of post weld heat treatment on the FSW quality of joined 14YWT plates will be investigated in the next FW work package.
\end{abstract}




\section{INTRODUCTION}

Friction stir welding (FSW) is a solid-state joining technique originally developed within the aluminum industry in 1991 that is being applied for joining thin sections of the advanced oxide dispersion strengthened (ODS) 14YWT in the Fuel Cycle Research and Development (FCRD) Program. The concept of FSW involves plunging a specially designed pin tool that rotates at high speeds into the work piece and traveling along the seam between the work pieces and joining by solid-state mixing. Heat produced by friction from contact between the rotating tool and work pieces allows material to flow around the tool during the translation of the rotating tool. As the tool travels along the seam, a cavity forms at the rear that becomes filled with material redistributed by the rotating tool to form the weld. The redistribution process causes the material to experience extreme levels of plastic deformation and thermal exposure that, in turn, can have a significant effect on microstructural changes in the weld zone.

Beginning in 2015, research in the FCRD program began the development of FSW for joining thin sections of $14 \mathrm{YWT}$ in the form of thin $(0.5 \mathrm{~mm})$ plate and ultimately thin wall tubing. In the previous fiscal year, a $~ 1 \mathrm{~mm}$ thick plate, or sheet, of 14YWT was produced by hot rolling with no edge cracking. The initial FSW experiment was performed on the $1 \mathrm{~mm}$ thick plate and involved a bead-on-plate weld in which the spinning pin tool is plunged into the plate surface, but does not penetrate the thickness of the plate, and then travels the length of the plate. The FSW run successfully produced a bead-on-plate stir zone on the $1 \mathrm{~mm}$ thick plate of 14YWT, but no characterization studies of the stir zone was performed by the end of FY15. Thus, the purpose of this report is to cover results of the microstructural analysis of the bead-on-plate stir zone and the initial research task on obtaining tensile properties from specimens fabricated from the stir zone in order to assess the quality of the FSW parameters used in the initial experiment.

\section{MATERIALS AND EXPERIMENTAL}

\subsection{Production of $0.1 \mathrm{~cm}$ thick $14 Y W T$ plate}

The plate used in the initial FSW experiment in FY15 was produced from 14YWT (SM13 heat). Figure 1 shows the $1.06 \mathrm{~cm}$ thick plate of 14YWT that was used in the rolling experiments to produce the $0.1 \mathrm{~cm}$ thick plate. Three rolling passes were performed after annealing the plate at $1000^{\circ} \mathrm{C}$ for $\sim 10$ minutes using both cross rolling (perpendicular relative to the extrusion direction) and parallel rolling orientations.

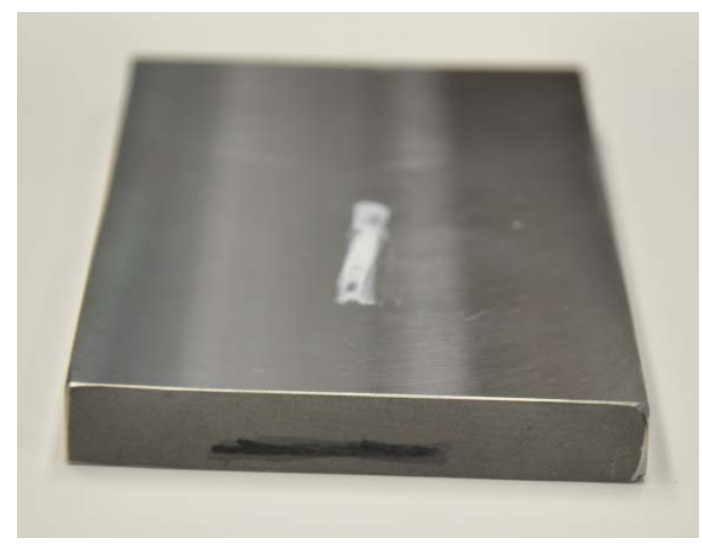

Figure 1. Digital image showing the $1.06 \mathrm{~cm}$ thick plate of $14 \mathrm{YWT}$ used for hot rolling to thinner plate thicknesses.

After the 3 rolling passes of $\sim 50 \%$ reductions in thickness (RIT) each, the $0.1 \mathrm{~cm}$ plate shown in Figure 2 was produced. Inspection of the plate showed no edge cracks were present, which was significant since 
the total amount of rolling deformation from the initial thickness of the extruded bar $(\sim 2.12 \mathrm{~cm})$ to the final thickness of $0.1 \mathrm{~cm}$ was $95.3 \%$ RIT.

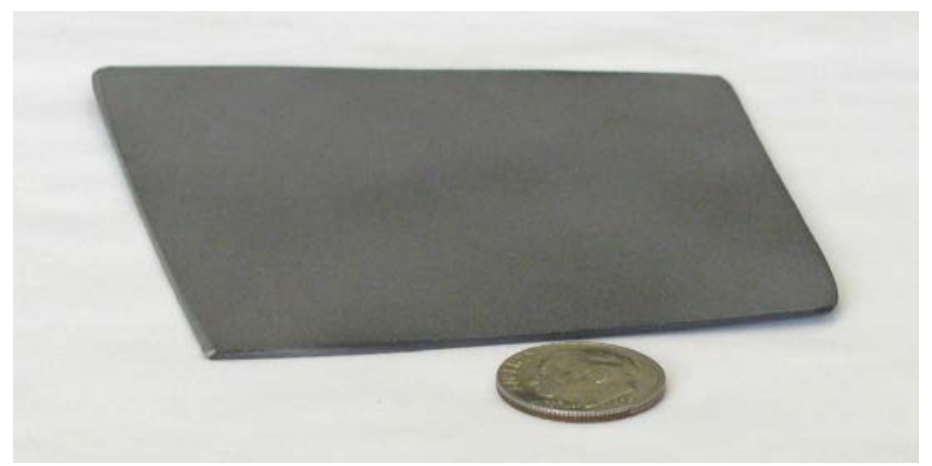

Figure 2. Digital image showing the $0.1 \mathrm{~cm}$ thick plate used in the first FSW experiment.

\subsection{Friction stir welding}

The initial FSW run performed on the $0.1 \mathrm{~cm}$ thick plate successfully produced a bead-on-plate stir zone shown as shown in Figure 3. The advancing and retreating sides of the spinning pin tool are shown in the Figure, in this case the pin tool traveled in the direction of the advancing side. From optical inspection, the bead-on-plate weld zone showed good mixing with no evidence of defects such as cavities. The swirl flow pattern observed for the bead-on-plate stir zone is commonly observed with FSW joints, which indicates that sufficient heat from friction generated between the rotating and traveling shoulder and pin tool with the 14YWT plate caused material to be redistributed from the front to the rear (retreating side) of the bead-on-plate stir zone. The success of the first FSW attempt was novel, since there have been no studies in the published literature that have attempted FSW on thin plates of ODS alloys.

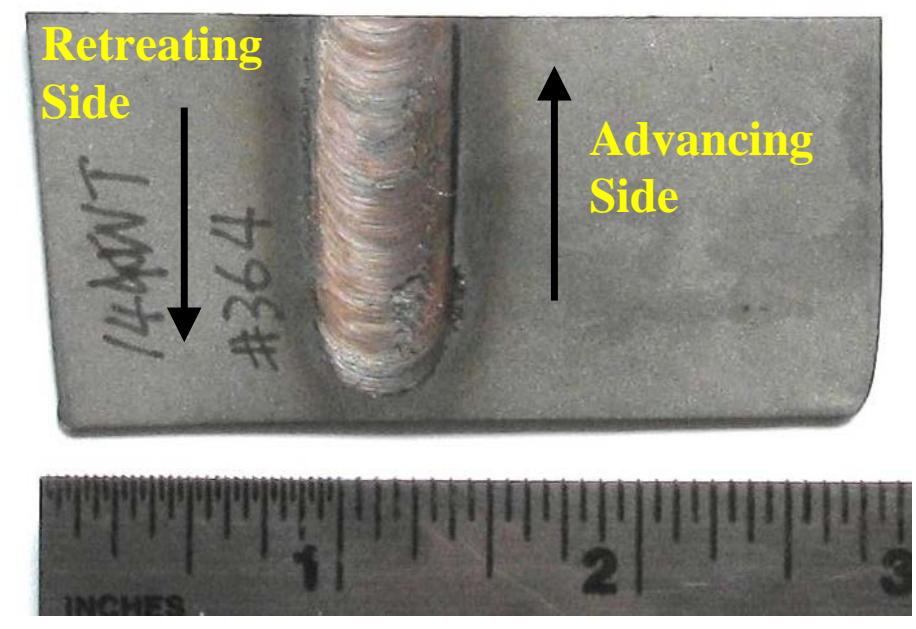

Figure 3. Digital image showing the bead-on-plate weld zone obtained by FSW on the $0.1 \mathrm{~cm}$ thick plate of 14YWT.

\subsection{Microstructure Characterization}

The microstrsuctural characaterization studies of bead-on-plate stir zone of the $0.1 \mathrm{~cm}$ thick plate of 14YWT consisted of optical microscopy (OM), Scanning Electron Microscopy (SEM) and Scanning Transmission Electron Microscopy (STEM). A cross-sectional specimen was cut from the $0.1 \mathrm{~cm}$ thick plate containing the FSW stir zone and mounted and polished using metallographic procedures. The 
polished specimen was carbon coated to reduce charging in the SEM. The polished sample was examined using optical microscopy, followed by examination using the JEOL 6500F (Field Emission) SEM using electron back scattered diffraction (EBSD) for grain size and texture anlaysis. Two specimens for STEM analsysis were prepared from the polished sample using the focused ion beam (FIB) in-situ lift-out technique FEI DualBeam in the LAMDA facility at ORNL. The thinned specimens were examined using the FEI Talos 200X STEM with the Super-X EDS 4-detector system also located in the LAMDA facility.

\section{RESULTS AND DISCUSSION}

\subsection{Microstructural characterization study}

Figure 4 shows a composite OM image of the entire $0.1 \mathrm{~cm}$ thick plate of $14 \mathrm{YWT}$ mounted in crosssection and polished to show the FSW bead-on-plate stir zone. Each square in the image represents a digitized optical micrograph obtained by translating the specimen relative to the lens for recording. The composite OM image reveals the stir zone width was $\sim 1.2 \mathrm{~cm}$ and was reduced in thickness from $0.1 \mathrm{~cm}$ (adjacent plate) to $\sim 0.07-0.08 \mathrm{~cm}$ near the center. A large crack is observed emanating from the bottom surface on the retreating side (left) of the $0.1 \mathrm{~cm}$ thick plate of 14WYT. This crack is outside the stir zone since it is on the bottom of the plate and lies away from the tapered pin tool that was plunged into the top surface during FSW but did not penetrate through the plate.

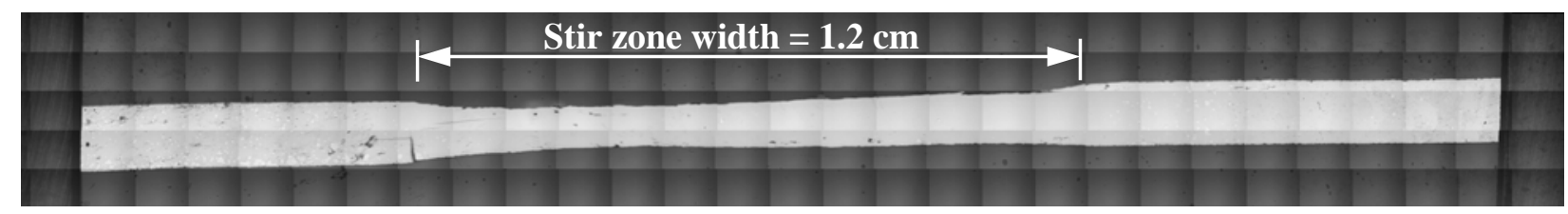

Figure 4. Composite OM image showing the entire cross-section view of the $0.1 \mathrm{~cm}$ thick plate of 14YWT containing the FSW bead-on-plate stir zone.

A composite of three OM images at a higher magnification showing the region containing the crack on the retreating side of the FSW bead-on-plate stir zone is shown in Figure 5. In addition to the large crack emanating from the bottom surface, several approximately horizontal cracks are observed both in the stir zone and outside the stir zone that lie closer to the top surface of the sample. This composite OM image also shows more clearly the reduction in thickness of the material associated with FSW bead-on-plate stir zone, which appears to be more severe on the top side compared to the bottom size. This observation is expected since the tapered pin tool did not penetrate though the $0.1 \mathrm{~cm}$ thick plate. Also shown in the composite image are the two regions used in preparing the lift-out/FIB specimens for STEM analysis. Their location indicates that their microstructures are representative of the stir zone. In both cases, the liftout/FIB specimens were oriented vertically in reference to the composite OM image. This orientation captures the deformation flow of material caused by the traveling spinning pin tool during FSW.

The BSE micrograph shown in Figure 6 was recorded at low magnification to show the grain structure texture on the retreating side of the bead-on-plate stir zone. The speckled contrast is due to the ultra-fine grain size, which is not resolved at the low magnification, and appears to be fairly homogeneous across the field of view. No interfacial boundary was observed that clearly defined the stir zone (SZ) from the thermo-mechanically affected zone (TMAZ). The BSE image shows that the horizontal cracks are not continuous, but contain small ledges protruding from the top and bottom internal surfaces. These features are also observed with the large crack that formed from the bottom surface of the $0.1 \mathrm{~cm}$ thick plate. The reason for the formation of the horizontal cracks is not known, but may be due to insufficient pressure from the spinning shoulder and pin tool during the FSW run. In this case, bands of material that are sheared on the advancing side of the spinning pin tool flow around to the retreating side where they are consolidated by forging processes. However, if the pressure is not high enough then the down ward force 
will not be sufficient to consolidate the sheared bands of material resulting in the horizontal cracks. Although this is conjecture, research will continue for explaining the formation of the cracks.

The microstructure observed away from the SZ in the unaffected zone is shown in Figure 7. The BSE micrographs were recorded at lower (Fig. 7a) and higher (Fig.7b) magnifications to show that the grain structured was highly elongated and oriented horizontally, i.e. in the plane of the $0.1 \mathrm{~cm}$ thick plate. The severe elongation and orientation of the grains was due to the $95 \%$ deformation during hot rolling to form the $0.1 \mathrm{~cm}$ thick plate of $14 \mathrm{YWT}$.

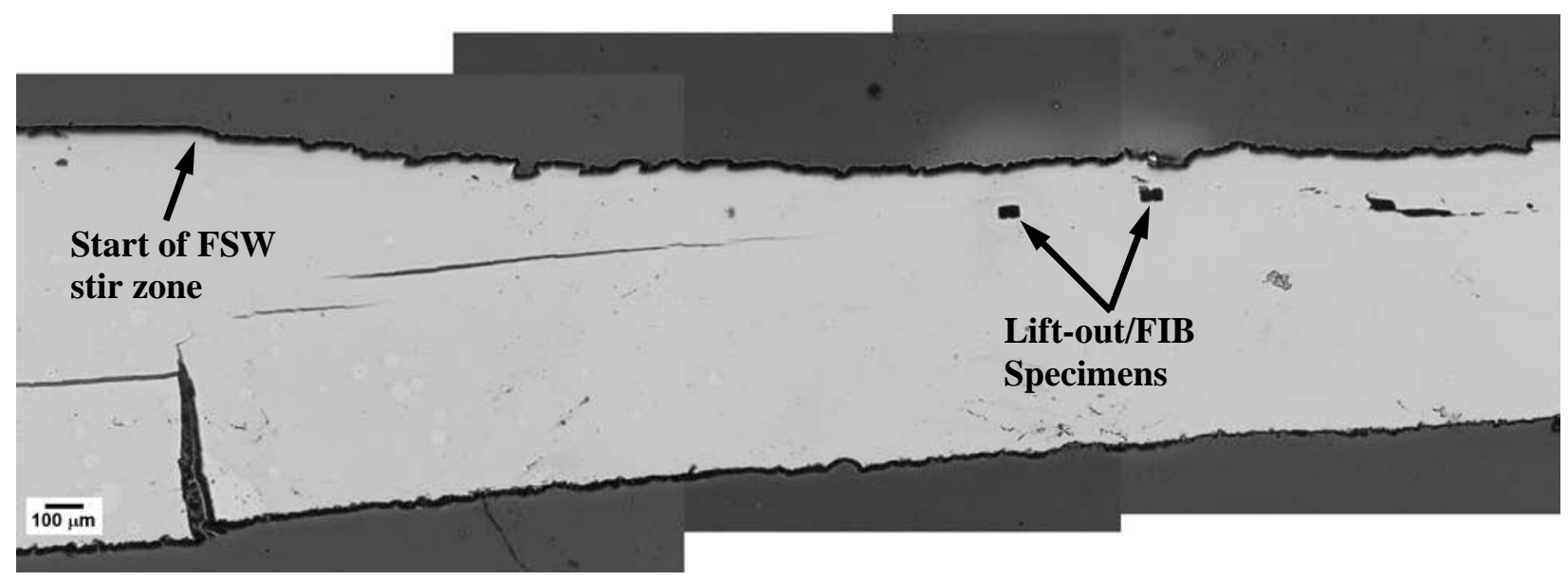

Figure 5. Composite of three OM images at higher magnification showing the location and orientation of several cracks and the two lift-out/FIB specimens on the retreating side of the bead-on-plate stir zone.

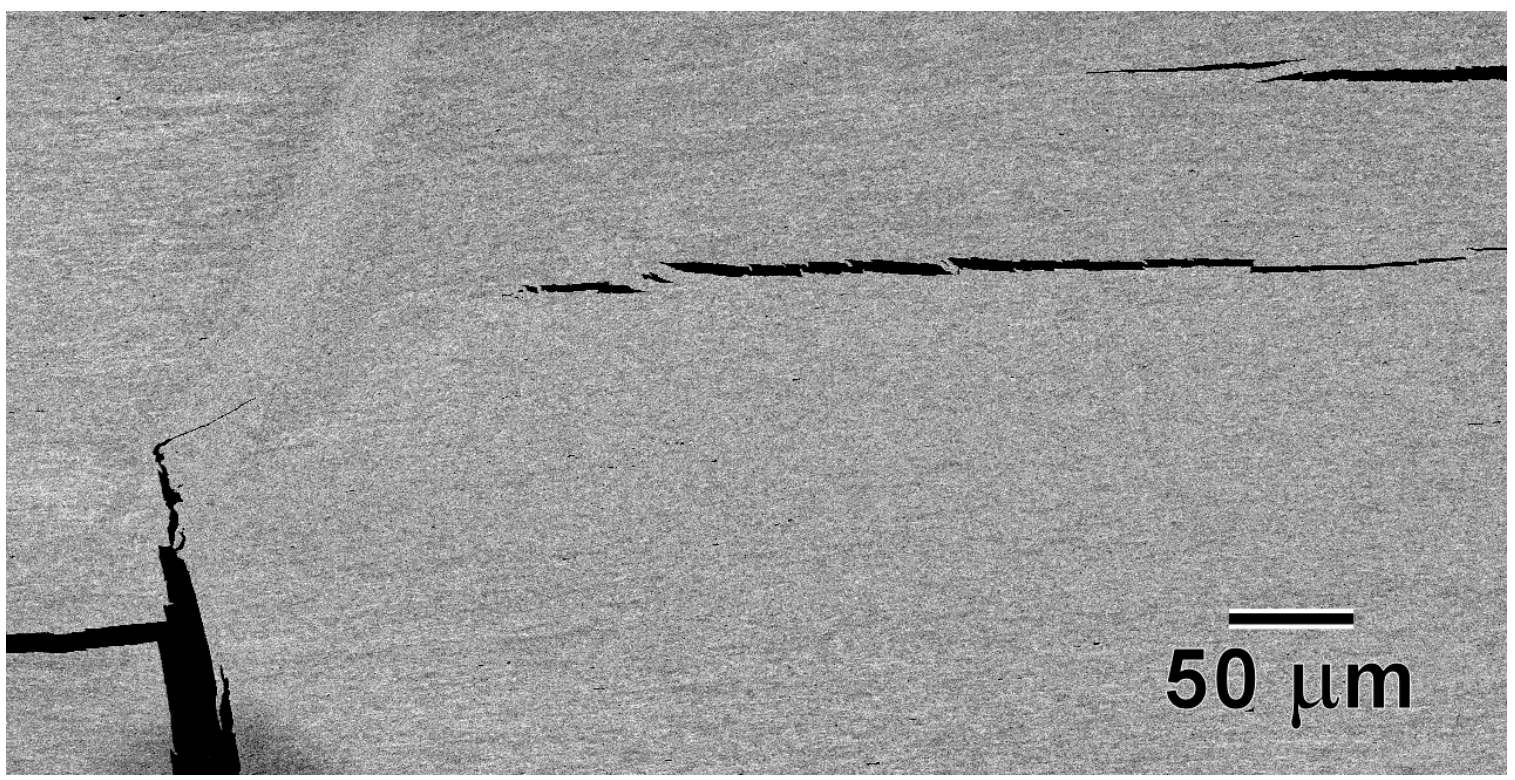

Figure 6. SEM BSE image at low magnification showing the grain structure associated with the stir zone and cracks on the retreating side of the bead-on-plate stir zone. 
Figure 8 shows BSE micrographs of representative regions for the TMAZ (Fig. 8a) and SZ (Fig. 8b) located on the retreating side of the FSW plate. Although the grains in the TMAZ are elongated and oriented horizontally, there appears to be some texture that cause variations in the observed contrast. This could be due to small variations in grain size and orientation in the TMAZ. In this case, the microstructure of the TMAZ still maintains similarities with that of the unaffected zone, but experiences some frictional heat and limited deformation caused by the spinning pin tool during FSW. Compared to the grain structure observed in the unaffected zone (Fig.7b), the grain structure observed in the SZ appears more isotropic and irregular in shape with some degree of increase in size. These observations indicate that the grains associated with the SZ experienced much higher levels of frictional heat and deformation.

(a)

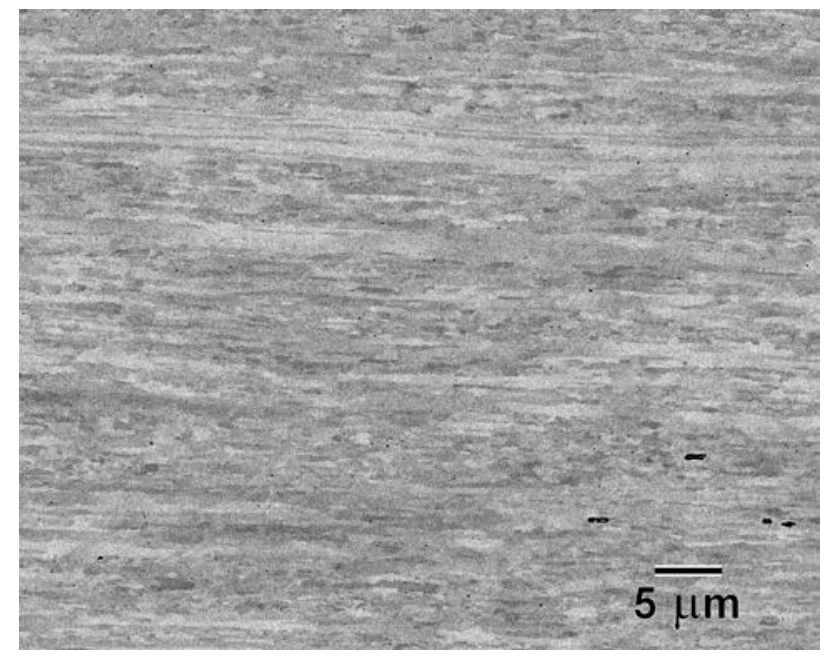

(b)

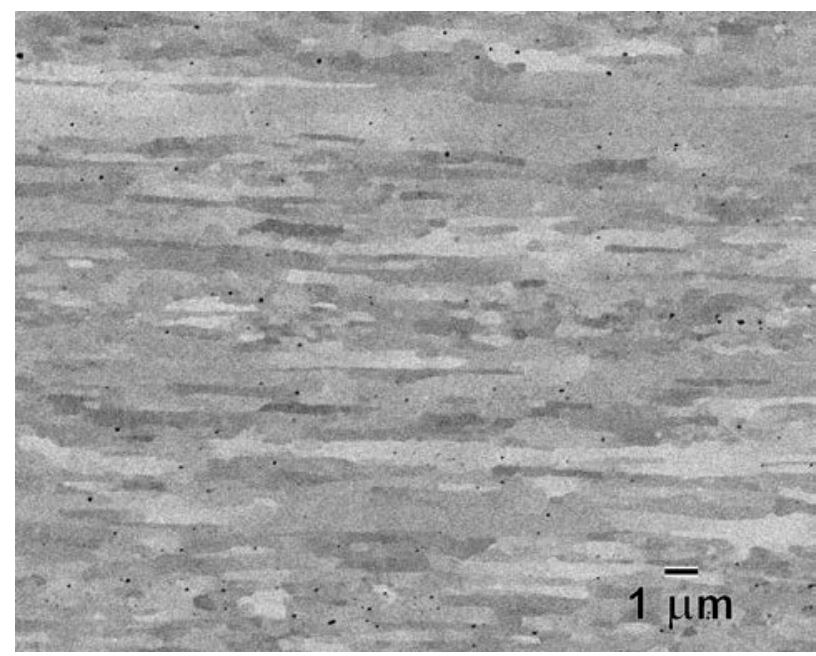

Figure 7. BSE micrographs showing the elongated morphology and horizontal orientation of the grain structure in the unaffected zone of the FSW sample at (a) lower and (b) higher magnifications.

(a)

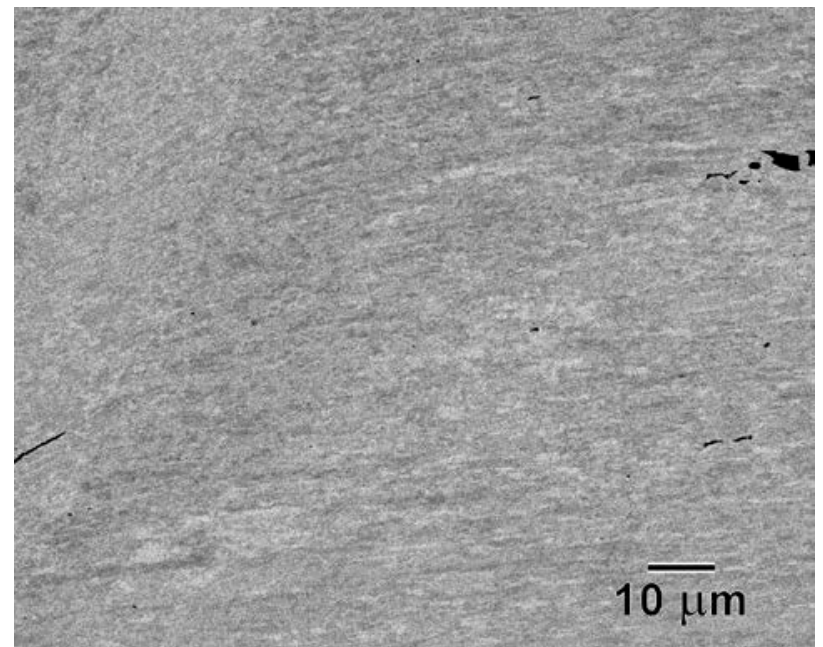

(b)

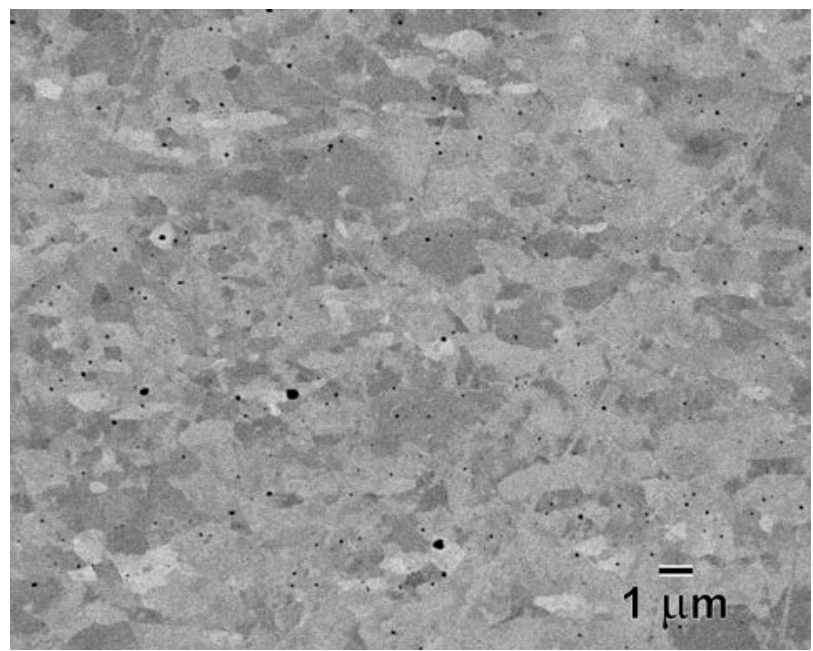

Figure 8. BSE micrographs showing the grain structure observed in the (a) TMAZ and (b) SZ in regions of the FSW sample located on retreating side.

The analysis of the SZ showed an inhomogeneous grain structure. Figure 9 shows BSE micrographs recorded near the top surface of the FSW plate that reveal variations in texture and grain size along with 
several horizontal cracks. These textured variations occur mostly in the horizontal directions, which may provide some evidence of the heat distribution and plastic deformation mechanisms that influence the flow of material during FSW. To explore these mechanisms in the future, investigations using electron back scattered diffraction (EBSD) and transmission Kikuchi diffraction (tKD) will be useful by obtaining details about differences in texture of the grain structures in the SZ.

(a)

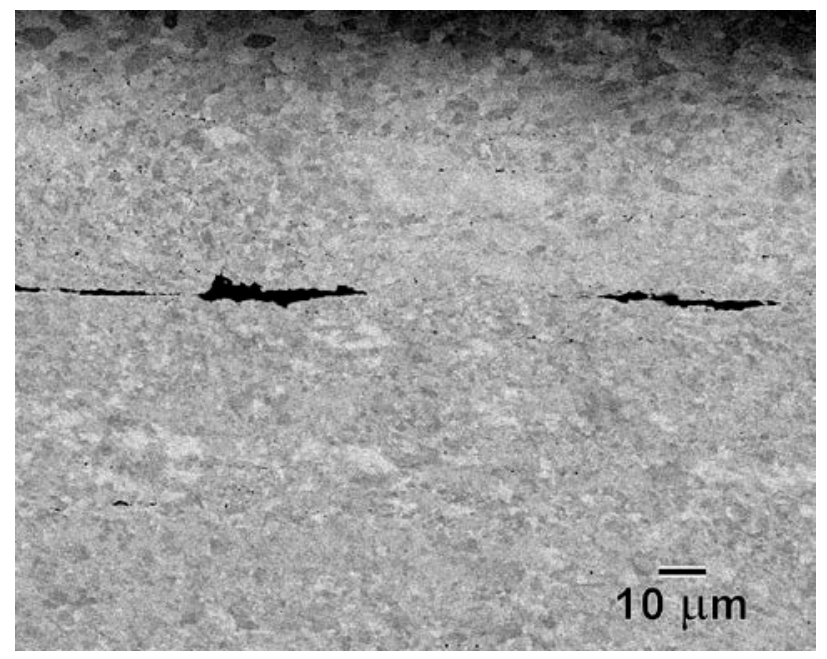

(b)

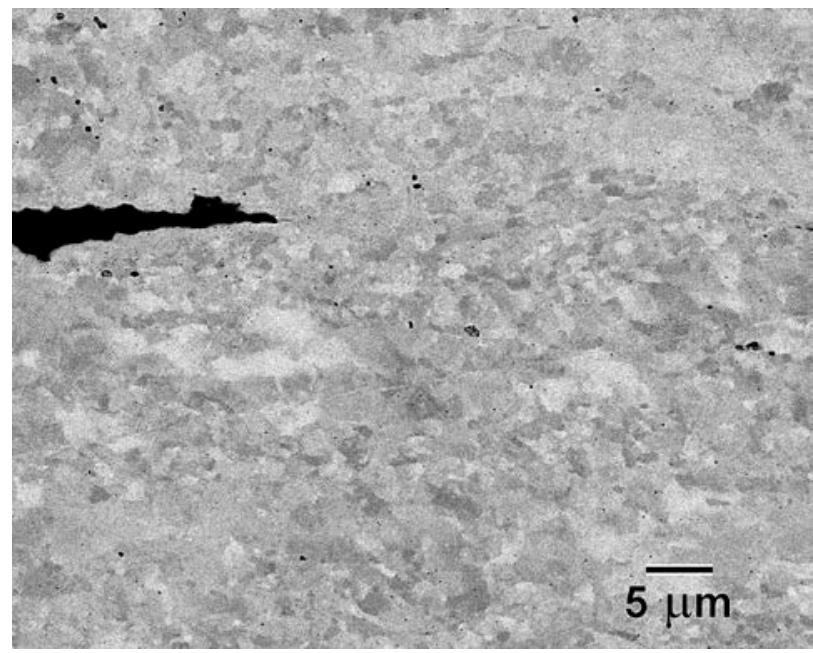

Figure 9. BSE micrographs showing the grain structure observed in the SZ in the vicinity of horizontal cracks at (a) lower and (b) higher magnifications.

The detailed microstructural analysis of the SZ was conducted using STEM imaging and high-spatial resolution element mapping. Figure 10 shows the grain structure observed in the SZ using bright-field (BF) and high angle annular dark field (HAADF) imaging conditions. The grains appear fairly isotropic in shape with a size of $\sim 500 \mathrm{~nm}$. This size compares closely with that determined by EBSD in the reference characterization study reported in FY milestone report (M3FT-15OR0203122), which was $430 \mathrm{~nm}$. Thus, at least in the region of the SZ that the FIB specimen was prepared from, the effects of FSW were not detrimental to grain coarsening. The evolution in grain morphology from highly elongated grains oriented horizontally prior to FSW to the isotropic grain morphology observed in the SZ suggests that dynamic recovery and/or recrystallization processes occurred. However, the fact that the grain size in the SZ did not change appreciably indicates that the temperature due to frictional heat and the magnitude of deformation were nearly optimized for the FSW parameters used.

The central grain observed in Figure 10 is shown at a higher magnification in Figure 11. The BF STEM micrograph (Fig. 11a) reveals a blocky-shaped particle on the grain boundary and a relatively high dislocation density with many of the dislocations appearing relatively straight. The accompanying X-ray EDS (XEDS) maps of Ti (Fig. 11b) and N (Fig. 11c) of the same area and the multivariate statistical analysis (MSA) of the XEDS data suggests that the large blocky-shaped particle is TIN, since the XEDS map showed no $\mathrm{O}$ associated with the particle. The Ti map also reveals the presence of a high number of Ti-rich nano-size particles aligned along the threading dislocations.

Figure 12 shows the high magnification STEM-EDS results from a junction of 3 separate and distinct grain boundaries. The STEM BF micrograph (Fig.12a) shows the dislocation structure in two grains oriented near Bragg diffraction conditions. The STEM HAADF micrograph (Fig. 12b) does not show much contrast associated with nano-size particles, but shows contrast variation between grains due to different orientations and diffraction conditions. The raw XEDS maps for Fe, Y, Ti, and O (Fig. 12c) 
reveal a high concentration of nano-size particles enriched with $\mathrm{Y}$, Ti and $\mathrm{O}$. The MSA of the data raw XEDS data (Fig. 12d) clearly reveals the Y-Ti-O particle distribution. There results show that some Y-Ti$\mathrm{O}$ particles have increased in size, yet there are many other particles that are still in the size range $<5 \mathrm{~nm}$. A more detailed particle size analysis is required. However, these microstructural results suggest that FSW is a viable method for joining ODS alloys.

(a)

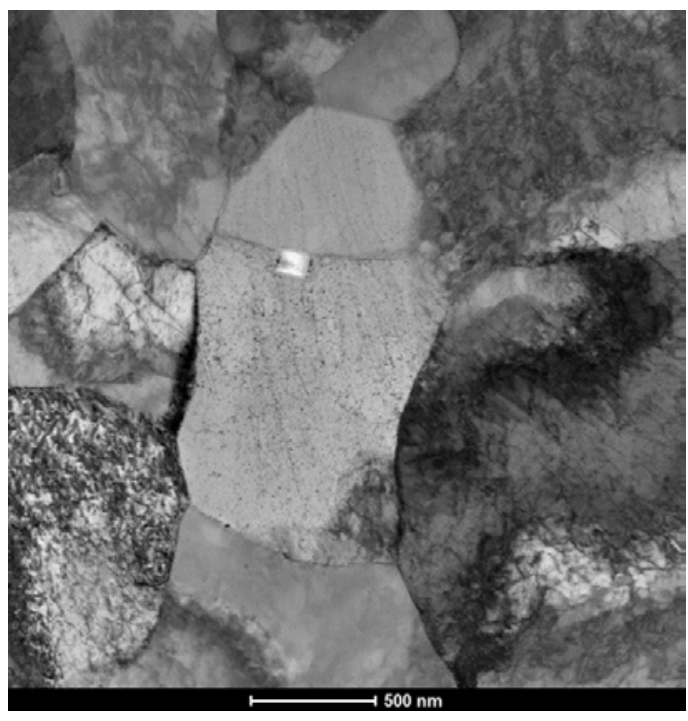

(b)

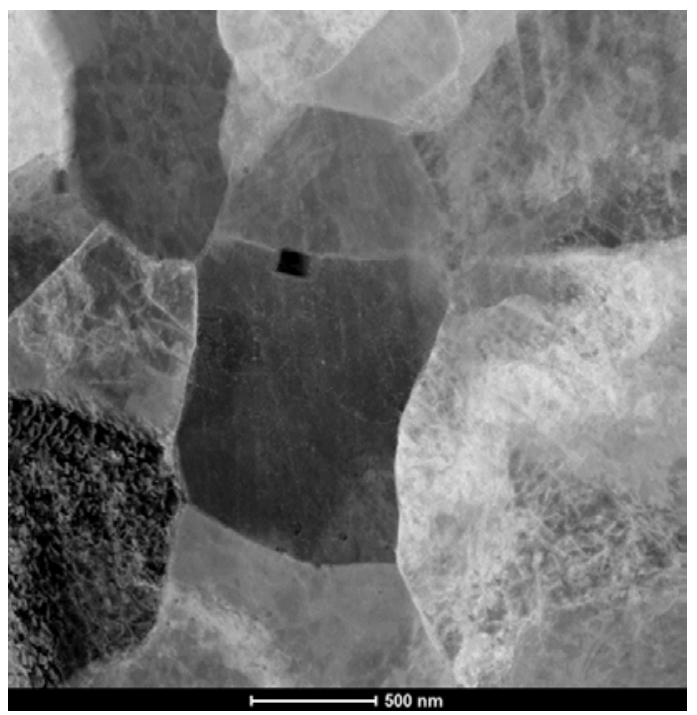

Figure 10. STEM micrographs (a) BF and (b) HAADF showing the grain structure observed in the SZ.
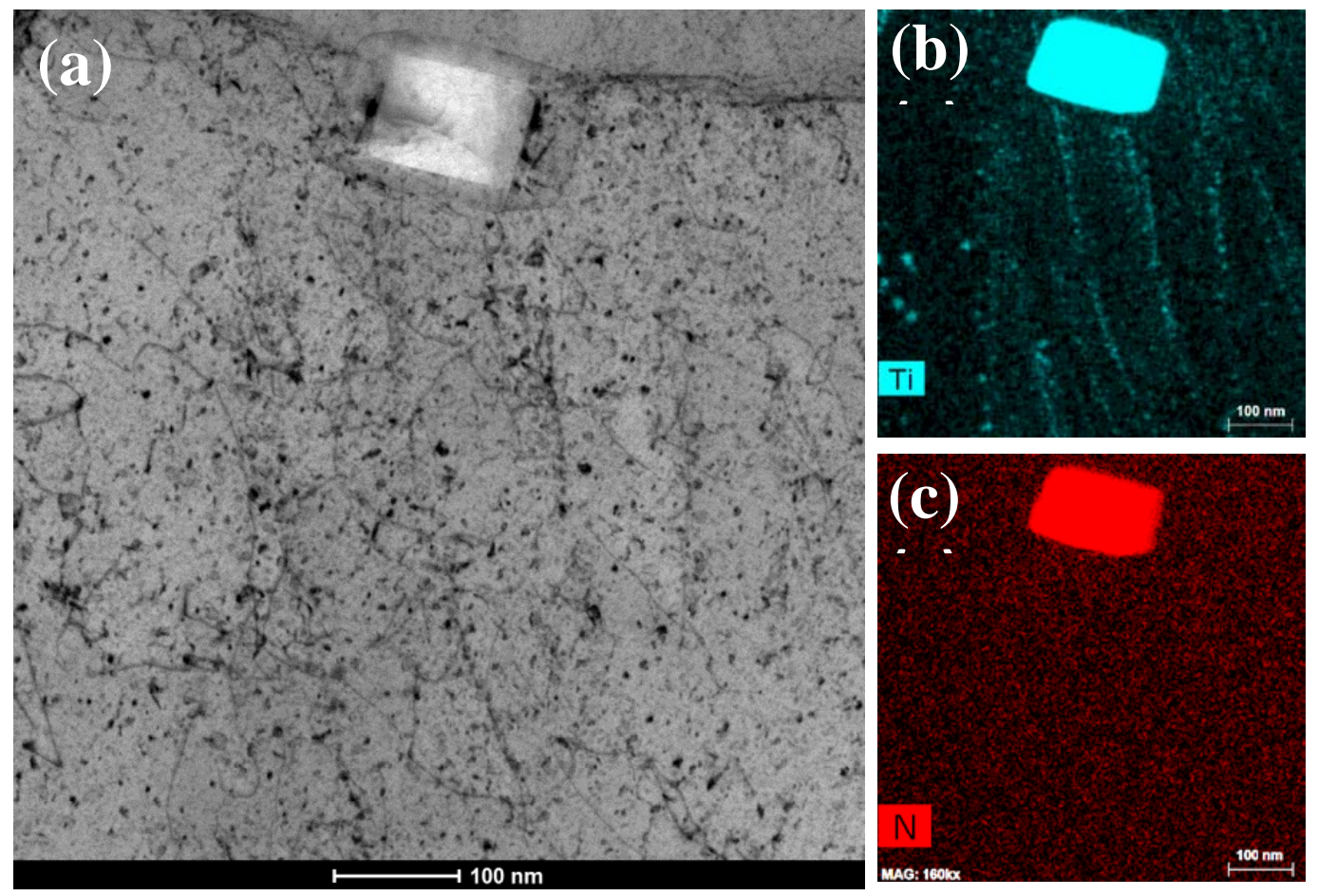

Figure 11. STEM analysis showing the presence of a large blocky-shaped Ti,N-rich particle on the grain boundary, a relatively high dislocation density and a high number of Ti-rich nano-size particles associated with straight dislocations. (a) STEM BF micrograph and EDS element maps for (b) Ti and (c) N. 

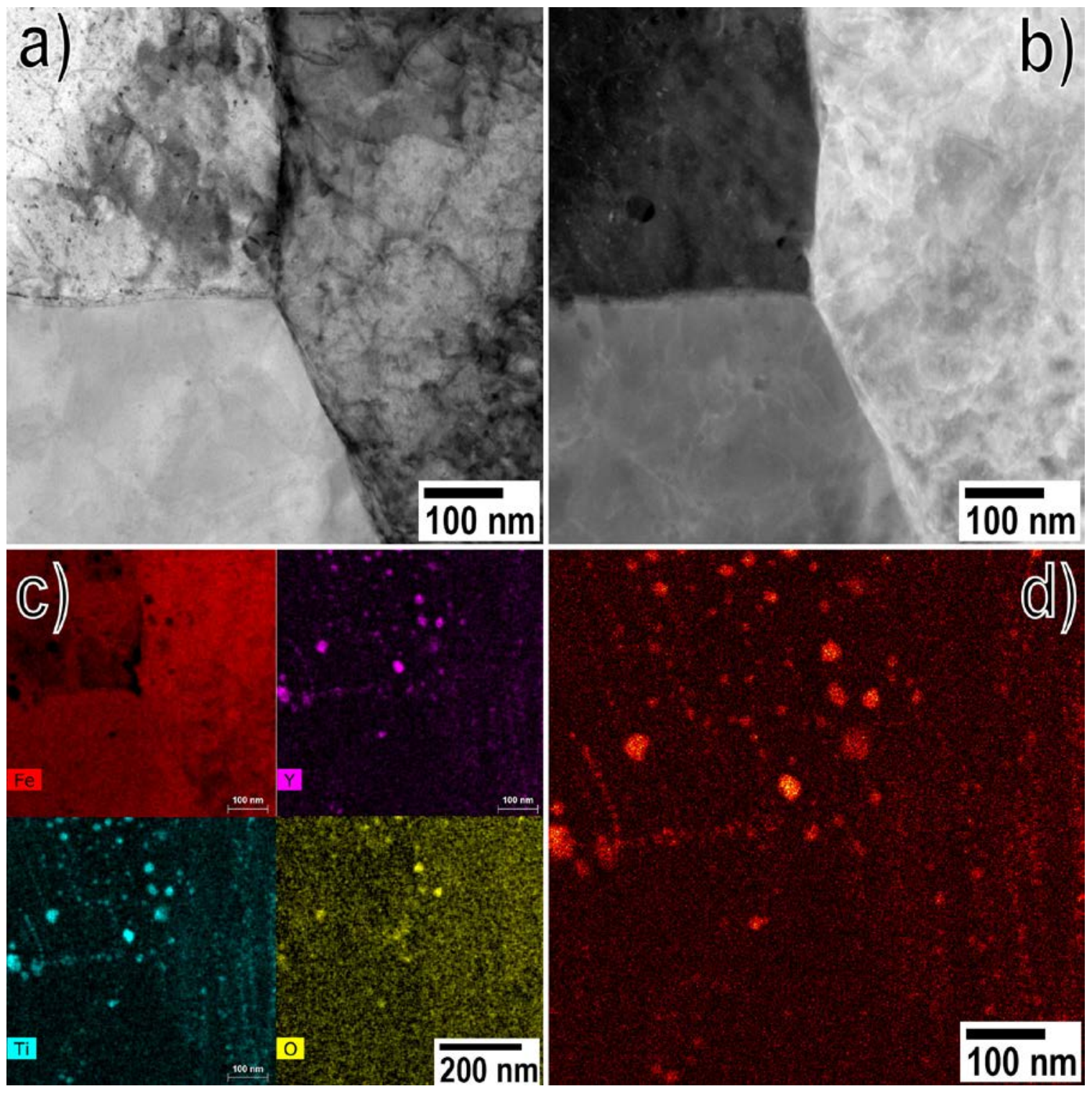

Figure 12. High magnification STEM-EDS results showing the distribution of Y-Ti-O particles near the junction between 3 grains. (a) BF, (b) HAADF, (c) raw XEDS maps for Fe, Y, Ti, and O and (d) results of the multivariate statistical analysis of the data in (c) showing the Y-Ti-O particle distribution more clearly.

\subsection{Mechanical property study}

The investigation of the mechanical properties of the bead-on-plate SZ produced by FSW was initiated using the digital image correlation (DIC) approach, which is based on optical extensometry. In this approach, the surface of a miniature tensile specimen is coated with droplets in order to measure localized extensions, or strain, along the gage during the tensile test. Figure 13 shows the layout of tensile specimens planned for the first DIC experiments. The goal was to fabricate an SS-1 tensile specimen spanning the SZ into each side of the base plate and five small SS-Mini-2 tensile specimens aligned parallel to the SZ with three from the SZ and two from the adjacent plate of 14YWT. Unfortunately, in the attempt to fabricate the SS-1 tensile specimen by wire electro-discharge, a sudden crack pop-in 
occurred that propagated through the $0.1 \mathrm{~cm}$ thick plate of 14YWT. This crack is shown in Figure 14 with a digital image of the pieces of the plate reassembled. The crack pop-in is observed on the right side of the SZ at a $\sim 45^{\circ}$ angle. Fortunately, 5 SS-Mini-2 tensile specimens were successfully fabricated from the plate, which is the region in the SZ in Figure 14 that is missing. The image in Figure 15 shows the location of the three SS-Mini-2 tensile specimens that were fabricated from the SZ. Their location is not centered as in the template shown in Figure 13, since two SS-Mini-2 specimens fractured during fabrication. The results showing the abrupt crack pop-in occurring in the $0.1 \mathrm{~cm}$ thick plate of 14YWT are most likely due to residual stresses due to the hot rolling steps and/or during the FSW run. Investigations in the next FY research will focus of residual stress measurements and the effects of post-weld heat treatments on FSW joining of 14YWT.

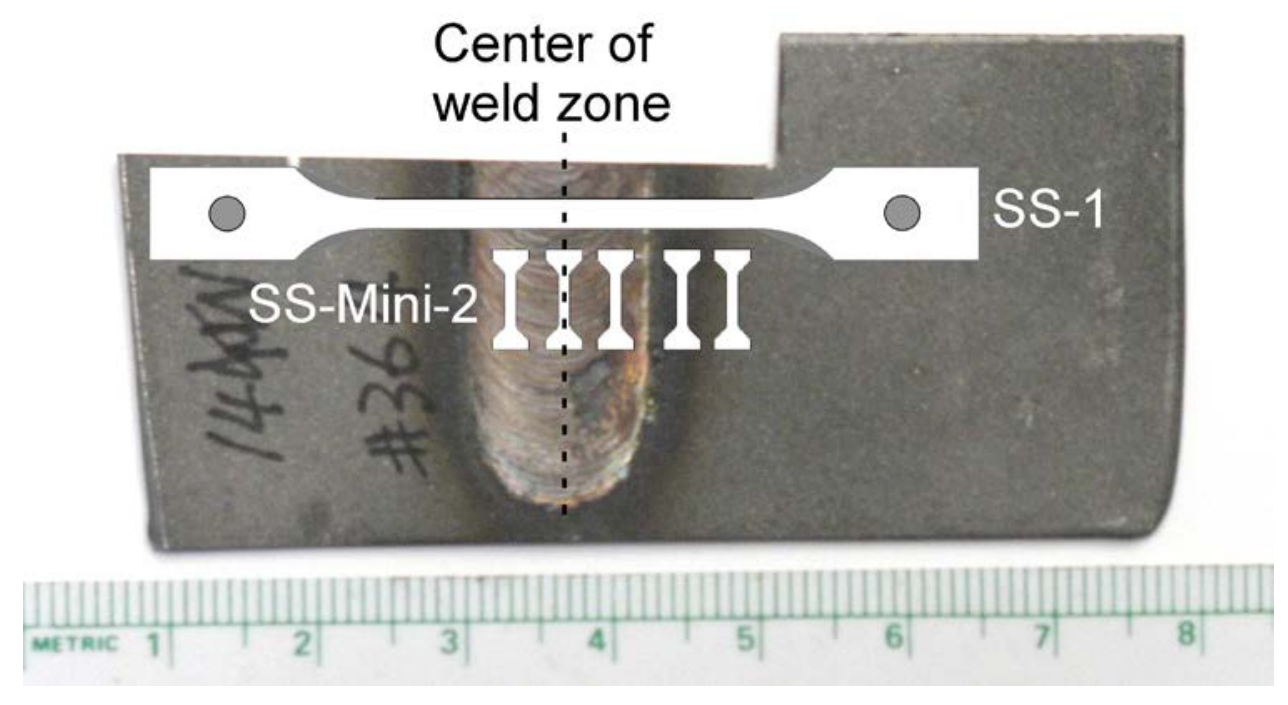

Figure 13. Template showing the layout of tensile specimens that were attempted to be fabricated from the $0.1 \mathrm{~cm}$ thick plate of $14 \mathrm{YWT}$ containing the bead-on-plate SZ.

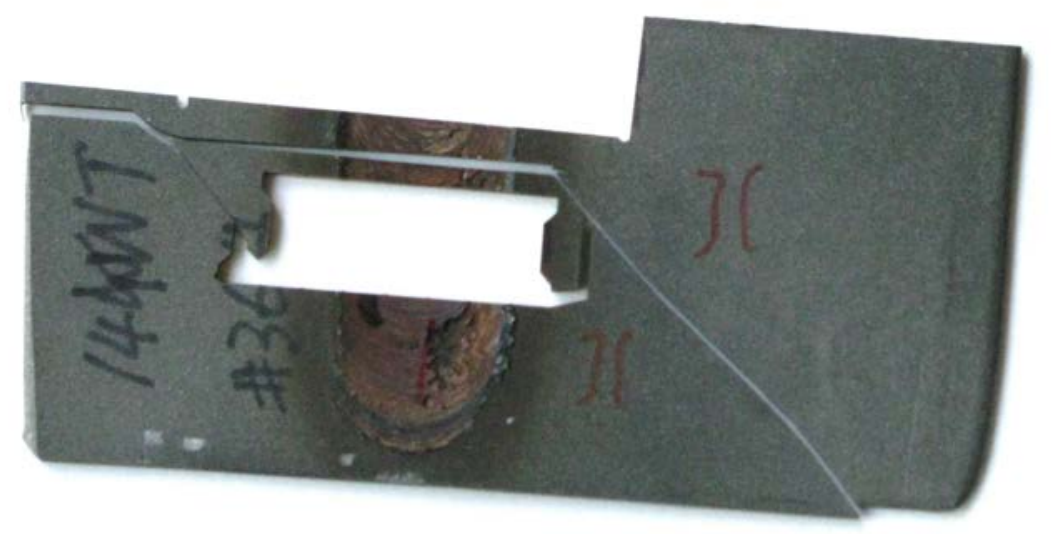

Figure 14. The $0.1 \mathrm{~cm}$ thick plate of 14YWT following the abrupt crack pop-in that occurred during fabrication of the SS-1 tensile specimen by wire EDM. 


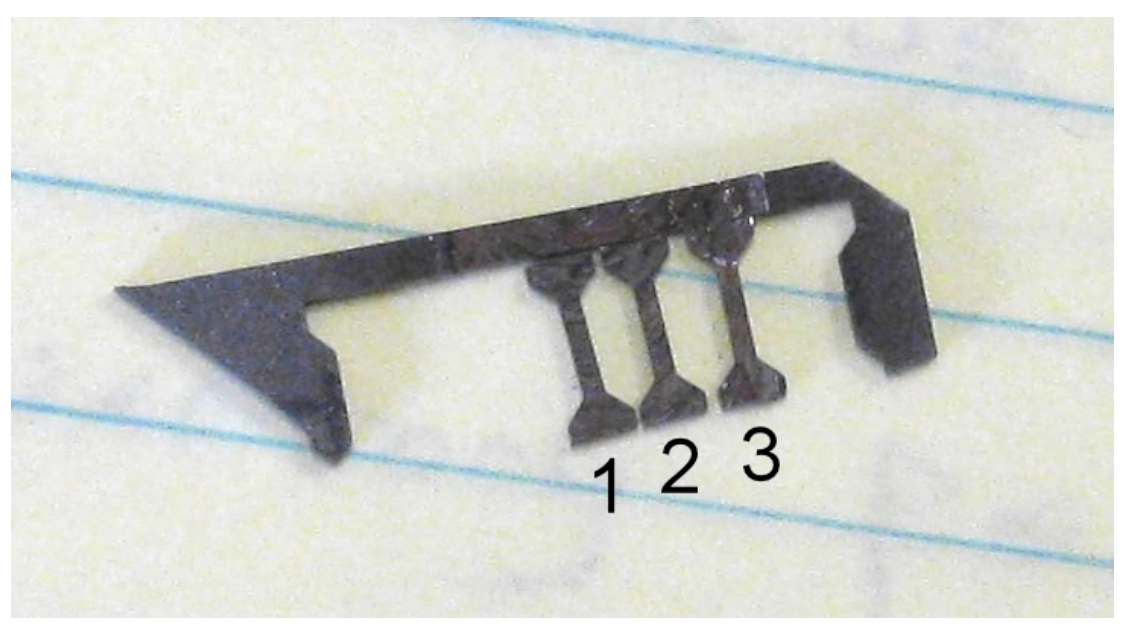

Figure 15. The location the three SS-Mini-2 tensile specimens fabricated from the bead-on-plate SZ.

The DIC analysis of the two SS-Mini-2 tensile specimens prepared from the $0.1 \mathrm{~cm}$ thick plate of 14YWT was conducted recently. Figure 16 shows the engineering stress-strain curves of the two 14YWT specimens obtained from tensile tests at room temperature. The values obtained for the yield and ultimate stresses and the uniform and total elongations are shown in Table 1. The strength and ductility of sample ${ }^{\#} 4$ was better than that of sample ${ }^{\#} 5$.

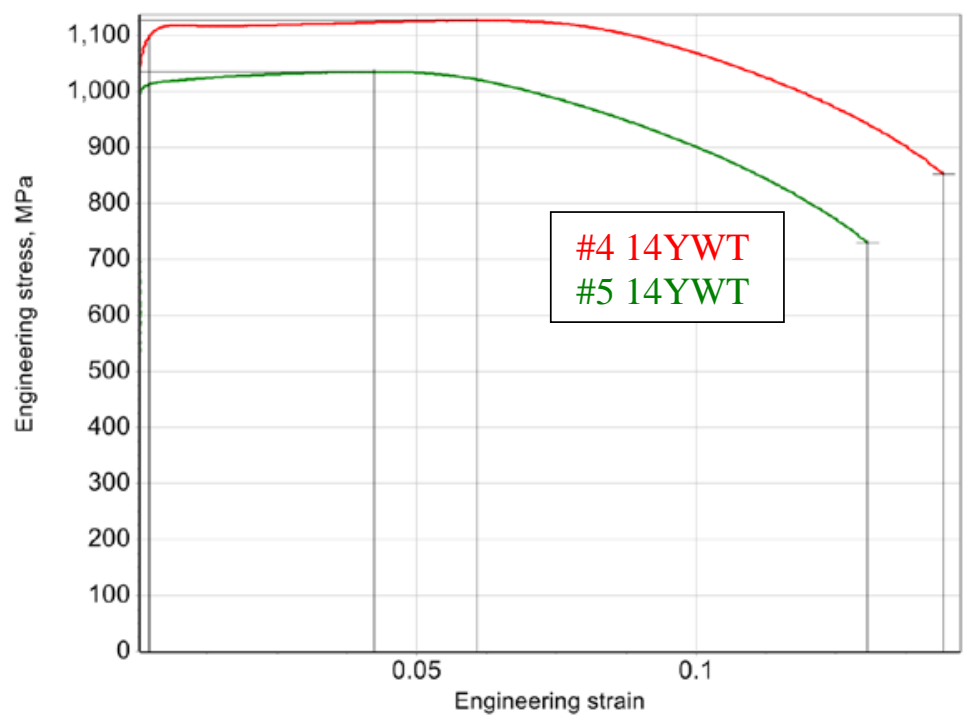

Figure 16. Engineering stress-strain curves of the two SS-Mini-2 specimens of 14YWT.

Table 1. Tensile properties of the two SS-Mini-2 specimens of 14YWT.

\begin{tabular}{|c|c|c|c|c|}
\hline$\#$ & $\begin{array}{c}\text { Yield stress, } \\
\text { MPa }\end{array}$ & $\begin{array}{c}\text { Ultimate stress, } \\
\text { MPa }\end{array}$ & $\begin{array}{c}\text { Uniform } \\
\text { elongation, \% }\end{array}$ & $\begin{array}{c}\text { Total } \\
\text { elongation, \% }\end{array}$ \\
\hline 14YWT,\#4 & 1095.67 & 1126.55 & 6.07 & 14.44 \\
\hline 14YWT,\#5 & 1012.7 & 1034.76 & 4.24 & 13.07 \\
\hline
\end{tabular}


The results of the DIC analysis of sample ${ }^{*} 4$ are shown in Figure 17. The image shows the SS-Mini-2 tensile specimen with the coating of droplets on the surface and a line along the gauge length representing the location of the strain distribution that was analyzed. The plot of Von Mises strain as a function of position along the gauge length shown by the line shows the distribution of strain for the 5 points of the stress strain curve. The results indicated that strain was localized in the left region of the gauge soon after yielding occurred and gradually intensified at this location until the instability at uniform strain was reached when the localized strain significantly intensified until failure of the specimen.

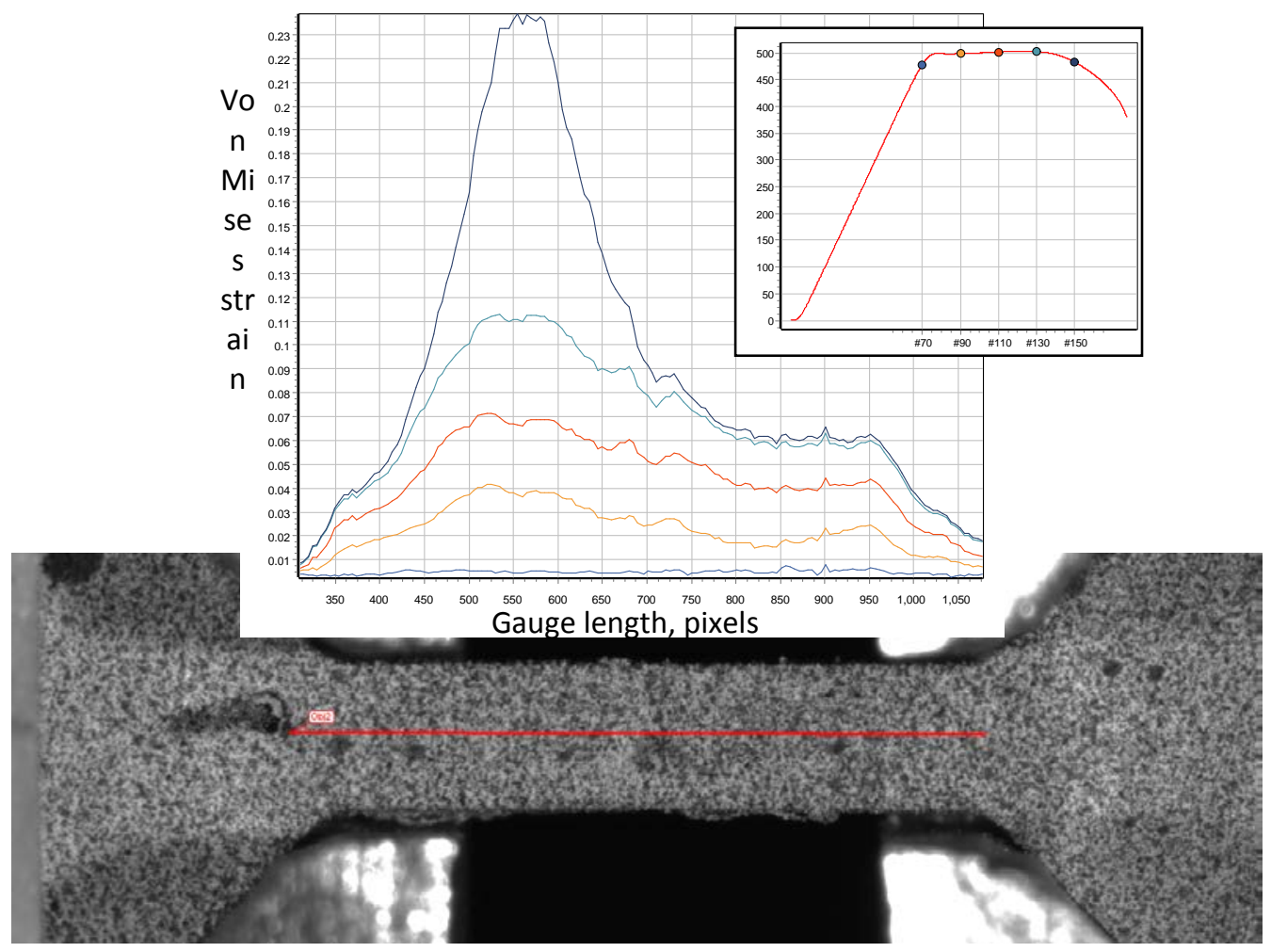

Figure 17. The strain distribution (Green-Lagrange strain tensor) along the gauge of specimen ${ }^{\#} 4$ at different time (Frame ${ }^{\#}$ ).

The results of the DIC analysis of sample ${ }^{\#} 5$ are shown in Figure 18. In this case, the results showed that strain was localized in the right side of the gauge after yielding and more rapidly intensified in this region. The location of the strain localization was determined to be too close to the gauge head of the SS-Mini-2 tensile specimen and the grip used for restraining the specimen along the shoulder most likely influenced the strain localization. However, it cannot be ruled out that inhomogeneity in the microstructure of the tensile specimen may have played a role in the location and intensification of strain in sample ${ }^{\#} 5$. Regardless of the actual mechanism the data correctly accounted for the location and intensification of strain during the tensile test. It will be interesting to compare these results with those that are planned for similar DIC tests on the SS-Mine-2 specimens prepared from the stir zone. Nevertheless, the DIC results obtained in this study are the first to be generated for the advanced ODS 14YWT ferritic alloy. 

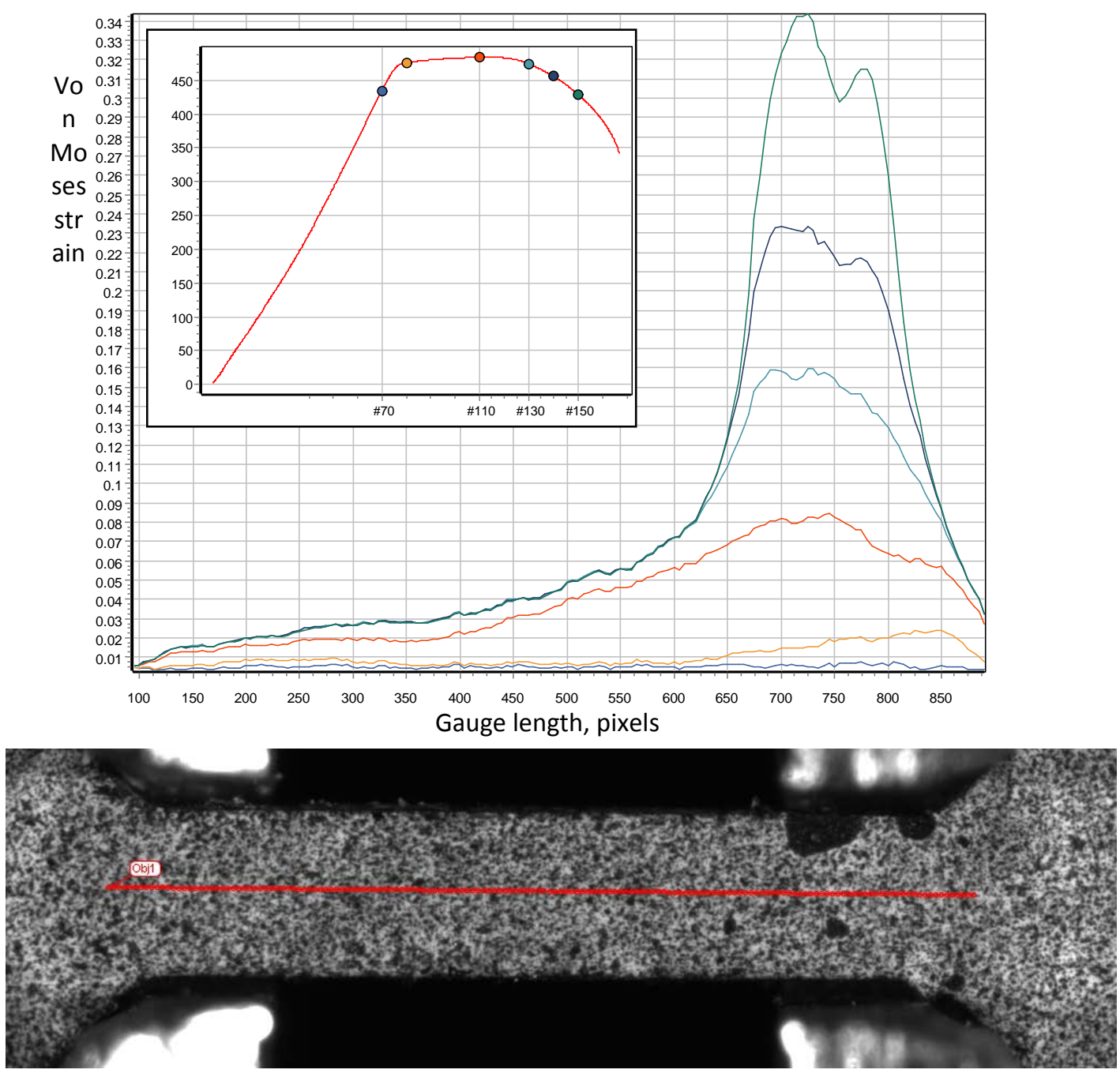

Figure 18. The strain distribution (Green-Lagrange strain tensor) along the gauge of specimen ${ }^{\#} 5$ at different time (Frame ${ }^{\#}$ ).

\section{SUMMARY}

The microstructural characterization study of the bead-on-plate stir zone (SZ) produced on a $0.1 \mathrm{~cm}$ thick plate of 14YWT by friction stir welding (FSW) was conducted and the mechanical properties study of the SZ was initiated using the digital image correlation (DIC) approach during testing of miniature tensile specimen. The results of the microstructural characterization study showed the grain structure in the SZ to have isotropic and irregular shape but very similar size compared to the highly elongated grains oriented horizontally with the plane of the plate that were observed in the unaffected zone of 14YWT. Several cracks oriented horizontally were observed mostly on the retreating side of the SZ in both the SZ and TMAZ. These cracks may have formed due to insufficient pressure being exerted on the top surface of the plate by the shoulder and pin tool during the FSW run. High resolution STEM-EDS analysis showed the presence of the $\mathrm{Y}$-Ti-O particles in the SZ, but that some particles exhibited coarsening. Overall, the FSW parameters used to produce the bead-on-plate SZ in the $0.1 \mathrm{~cm}$ thick plate of 14YWT were nearly optimized. The results of the digital image correlation (DIC) analysis of the two SS-Mini-2 tensile 
specimens fabricated from the $0.1 \mathrm{~cm}$ thick plate of $14 \mathrm{YWT}$ showed that the specimens exhibited high strength and good ductility. However, strain localization occurred in one of the specimens during the tensile test that was too close to the grips, which invalidated the data from the DIC analysis. This was surprising since the abrupt crack pop-in that occurred in the $0.1 \mathrm{~cm}$ thick plate of 14YWT during fabrication by wire EDM suggested that residual stresses were high. Residual stress measurements and the effects of post weld heat treatment on the FSW quality of joined 14YWT plates will be investigated in the next FW work package. In addition, DIC experiments will continued when the SS-Minni-2 tensile specimens are prepared from the SZ of the $0.1 \mathrm{~cm}$ thick plate of 14YWT 